\title{
Experiências em economia solidária e seus múltiplos sentidos
}

\author{
Alicia Ferreira Gonçalves \\ Universidade Federal do Ceará (UFC)
}

\section{Experiências em economia solidária e seus múltiplos sentidos}

Resumo: Este artigo apresenta relatos etnográficos de experiências em economia solidária no estado do Ceará. Os relatos dessas experiências foram revelados por meio de observação participante, de documentos oficiais fornecidos pelas entidades, de entrevistas qualitativas, de aplicação de questionários e de conversas informais, realizadas com diversos atores que compõem o campo da economia solidária no Ceará ao longo de três anos de pesquisa etnográfica. A linha de argumentação desenvolvida no presente artigo é a de que conceitos como economia solidária, solidariedade e reciprocidade assumem múltiplos sentidos nas experiências contemporâneas dos agentes vinculados ao campo da

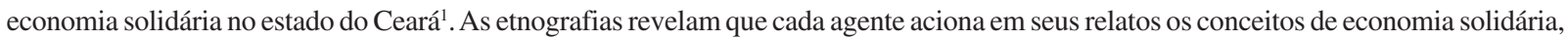
solidariedade e de reciprocidade (re)significando-os segundo interesses estratégicos, conjunturas específicas e valores oriundos de tradições particulares as quais estão vinculados, articulando, portanto, duas dimensões: estrutura e processo.

Palavras-chave: economia solidária, solidariedade, reciprocidade, políticas públicas.

\section{Experiences in Solidarity Economics and its Multiple Meanings}

Abstract: This article presents ethnographic reports of experiences in economic solidarity in Ceará State. The reports of these experiences were revealed by means of participant observation, through analysis of official documents supplied by entities, qualitative interviews, that used questionnaires and informal conversations conducted with various actors in the field of solidarity economics in Ceará during the three years of ethnographic research. The article maintains that concepts such as solidarity economics, solidarity and reciprocity assume multiple meanings in the contemporary experiences of the agents linked to the field of solidarity economics in Ceará State $^{1}$. The ethnographies reveal that each agent activates in his reports the concepts of solidarity economics, solidarity and reciprocity, in a way that gives them new meanings according to strategic interests, specific situations and values linked to particular traditions to which they are linked, articulating, therefore, two dimensions: structure and process.

Key words: solidarity economics, solidarity, reciprocity, public policies. 
O mais difícil é esse lado. Esse choque entre a economia burguesa, de capital evoluído para a economia de quem está iniciando, que é trabalhar com o mesmo grupo que a gente sabe que é essencial que são os mais pobres.

Manoel Evangelista de Brito, poeta popular.

\section{Introdução}

O presente artigo apresenta relatos etnográficos das experiências contemporâneas dos empreendimentos econômicos solidários vinculados à Agência de Desenvolvimento Solidário (ADS) do estado do Ceará $^{2}$. A ADS foi constituída pela Central Única dos Trabalhadores (CUT) no ano de 1999 e a sua experiência piloto se desenvolveu no estado do Ceará, com a criação de seu primeiro escritório estadual. AAgência tem como foco central fortalecer os empreendimentos de economia solidária por meio de cursos de capacitação, elaboração de projetos e de alavancagem de recursos financeiros oriundos das políticas públicas. Ao longo de três anos de pesquisa realizei a aproximação etnográfica junto à $\mathrm{ADS} / \mathrm{CE}$, em oito empreendimentos econômicos em diversos segmentos de mercado no estado do Ceará e em dois empreendimentos na Praia do Forte no estado da Bahia, que denomino neste texto como casos etnográficos.

Neste artigo vou apresentar os relatos de dois casos etnográficos que se configuram como experiências exemplares. Eles nos permitem refletir sobre os múltiplos sentidos que a economia solidária assume devido a interesses, contextos e conjunturas específicos e valores atados às tradições culturais particulares, articulando em suas respectivas experiências duas dimensões: estrutura e processo ou ação social e estrutura ${ }^{3}$.

A etnografia nos revela que os empreendimentos econômicos solidários se constituem como um universo simbólico distinto e específico que articula simultaneamente no tempo e no espaço várias esferas da vida social ${ }^{4}$ : simbólica, política, econômica, geográfica, ecológica, religiosa, de gênero e étnica, configurando um "fato social total" (MAUSS, 1974). Nesse sentido, os experimentos em economia solidária podem assumir vários formatos e se originarem de diferentes "razões práticas" (BOURDIEU, 1997). No contexto da etnografia que realizei, os empreen- dimentos foram constituídos a partir dos movimentos sociais (rural e urbano), como é o caso da Coopsol e o da Cooperativa de Crédito Rural de Jaguaretama; do poder público local, como a Coopremarce; da confluência de interesses do poder público local, das instituições financeiras e de iniciativas de grupos de pessoas, como é o caso da Coopernéctar; da prática terapêutica como a Coopvida e a Coopcaps; de exempregados de empresas estatais que foram privatizadas, como é o caso da Coopece; e de grandes empreendimentos capitalistas, como a Cooperativa de pescadores da Praia do Forte.

Os empreendimentos traçaram trajetórias específicas, constituíram identidades particulares e se defrontam com limitações similares. Portanto, há diferenças e especificidades entre os empreendimentos e ao mesmo tempo, similaridades. Ao longo desse percurso, alguns empreendimentos teceram em suas relações sociais teias sólidas de reciprocidade, enquanto outros não conseguiram construir laços sociais sólidos e coesos e fundamentados em relações simétricas, para transcender o individualismo exacerbado, o auto-interesse e o clientelismo político. Alguns empreendimentos construíram a sua viabilidade econômica adotando uma racionalidade empresarial capitalista, embora falem em nome da economia solidária.

Neste artigo vou apresentar relatos de duas experiências: a primeira é uma cooperativa formada por mulheres costureiras em uma região periférica da capital cearense. Essas mulheres mesclaram em seu cotidiano lutas sociais e de gênero (combate à violência contra a mulher) e espiritualidade. Ao longo de sua trajetória como cooperativa e grupo coeso teceram intensos laços de solidariedade e de reciprocidade e, neste propósito, incorporaram o sentido profundo de um projeto de economia solidária da perspectiva daquelas pessoas excluídas do exercício da cidadania e de seus direitos fundamentais. A segunda experiência é uma cooperativa de crédito situada na zona semiárida do estado, formada por assentados da reforma agrária que incorporaram o projeto da economia solidária a partir de suas próprias categorias simbólicas ou de seus respectivos sistemas classificatórios, isto é, incorporaram a economia solidária via clientelismo político. Deste modo, ao invés da economia solidária se constituir como uma possibilidade de acesso ao exercício da cidadania e aos direitos básicos, ela reproduz as relações clientelistas e a exclusão social. 


\section{Caso 1: Coopsol e a utopia da nova sociedade}

O primeiro caso etnográfico relata a experiência contemporânea da Cooperativa de Crédito Solidário (Coopsol), localizada em uma região periférica de Fortaleza $^{5}$. A Cooperativa, desde o ano 2000, atua no segmento de confecção, produzindo peças íntimas e roupas masculinas, femininas, bolsas, faixas e fardamentos e está formada em sua grande maioria por mulheres costureiras. A cooperativa está situada na região denominada de Grande Jangurussu, uma área geográfica considerada de risco na cidade de Fortaleza em função dos graves problemas sociais que ali se concentraram, que envolvem, ausência de moradias dignas, invasão de terras, educação, saneamento básico, saúde, violência contra a mulher, criminalidade, tráfico de drogas e transporte ${ }^{6}$. A gênese da Coopsol está imersa, como diria Karl Polanyi, nas relações sociais da comunidade, isto é, está mesclada às lutas sociais empreendidas pela população que veio residir nessas comunidades. Lutas pela moradia, por saneamento básico, água, energia elétrica, escolas, postos de saúde, transporte, segurança e, principalmente, pelo emprego. Nesse contexto, a economia solidária, por meio de seus empreendimentos, teria o potencial de gerar emprego e renda para essa população.

Polanyi $(2000$, p. 65) se refere às experiências das sociedades ditas primitivas, nas quais a atividade econômica está embedded, imersa ou submersa em relações sociais, em contraposição às sociedades industriais capitalistas, onde há supostamente uma autonomização da atividade econômica, e uma subordinação das demais esferas ao plano econômico. No caso das sociedades ditas primitivas, é a própria troca ancorada na reciprocidade, na redistribuição e imersa nas relações sociais que configura um sistema econômico que garante a coesão e a estabilidade social. Nas sociedades industriais é o próprio sistema econômico fundado sob uma economia de mercado 'auto-regulado' que desagrega o tecido social. Poderíamos pensar, por meio da experiência da Coopsol, que a solidariedade, tecida em suas relações sociais, poderia construir a coesão social naquela comunidade?

A comunidade foi apoiada inicialmente por dois missionários italianos, os padres Francisco Mouser e Luis Fornasier, ambos vinculados à Pastoral Operária, e pela Associação Santo Dias. A semente plantada pelos padres deu frutos, dentre elas, a própria cooperativa, segundo os relatos da presidente da cooperativa: "Quando eles chegaram tudo mudou". As principais contribuições dos padres foram a conscientização política das pessoas que residem nas comunidades e a organização das lutas sociais, segundo os relatos das sócias da cooperativa e de Manoel Evangelista de Brito, poeta popular e mili- tante da pastoral, um dos personagens centrais do Conjunto Palmeiras, da cooperativa e militante da economia solidária na comunidade ${ }^{7}$.

Em 1989, foi constatado alto índice de desemprego, a partir dessa questão aliada à ausência de saneamento básico, escolas e segurança, a pastoral delineou a sua atuação para a formação profissional, educação básica e cidadania. Não se tratava apenas de reivindicar saneamento básico e emprego, mas, sobretudo, de formar consciências críticas, educar para o exercício da cidadania e para a construção de uma nova sociabilidade, por meio de projetos de economia solidária naquela região. Neste sentido, há uma dimensão pedagógica significativa subjacente às ações da pastoral que deve ser considerada, que é justamente a de manter a identidade da classe trabalhadora, o resgate da auto-estima e a construção de uma nova cultura do trabalho baseada no espírito coletivo, de partilha e nos laços de solidariedade, "[...] portanto, sem as relações de exploração, que são próprias do capitalismo" (PASTORAL OPERÁRIA, 2005, p.1).

Trata-se de uma visão de mundo que é peculiar à Pastoral Operária. Pois para esta entidade,

A verdadeira experiência da economia solidária é a que rompe com a lógica do sistema capitalista. Que não só garanta a renda, mas que trabalhe a questão da cidadania, do protagonismo dos trabalhadores, tendo como base sólida, os princípios da igualdade e solidariedade (PASTORAL OPERÁRIA, 2005, p.1-2).

Embora tenham incorporado o sentido profundo da economia solidária a partir do contato intenso com a Pastoral na figura dos padres Fornasier e Chico, as sócias da cooperativa receberam uma formação sólida em cooperativismo, auto-gestão e economia solidária, por meio dos cursos de capacitação ministrados pela incubadora de cooperativas, pela Unitrabalho e pela ADS.

No ano de 2000, foram formados os grupos de produção que compõem a Coopsol, os quais estão distribuídos geograficamente nos bairros que formam o Grande Jangurussu. No bairro João Paulo II, situa-se a sede da cooperativa onde se produz roupas masculinas, femininas, faixas e fardamentos, no Conjunto Palmeiras e no Parque Santa Maria se produz peças íntimas. Os grupos, à exceção da sede, atuam em espaços físicos emprestados das Comunidades Eclesiais de Base ou da Associação Santos Dias. Do ponto de vista do exercício da auto-gestão e do cooperativismo, os grupos estão tendo êxito, pois as questões são debatidas e as decisões são tomadas a partir do consenso que se forma dentro dos grupos que atuam com autono$\mathrm{mia}^{8}$. Uma vez por mês, cada grupo de produção realiza reuniões com a participação das sócias; 
uma vez por ano é realizada uma assembléia com a presença de todas as cooperadas da Coopsol; e para assuntos extraordinários convocam-se reuniões com a presença de todas as sócias. Em 2005, enquanto se registrava essa pesquisa, as cooperadas discutiam a possibilidade da reforma da sede, para unificar e concentrar em um mesmo espaço físico os três grupos de produção. Foi acordado que a elaboração do plano de negócios caberia à Unitrabalho. Atualmente a cooperativa está participando do projeto do Mercado Solidário ou da Central Solidária, com financiamento do Banco do Nordeste do Brasil (BNB) e coordenação da incubadora de cooperativas e da ADS.

Segundo Aquino (2007, p. 9),

A maioria dos sócios são mulheres, na faixa etária de 25 a 60 anos de idade, casadas e/ou separadas, com uma média de 03 a 05 filhos, desempregadas, com renda familiar de no máximo 02 salários mínimos, provinda do trabalho do marido ou dos filhos. Neste sentido, a busca pelo trabalho cooperativo, para a maioria das sócias é motivada pela necessidade de obter uma renda básica ou complementar para a família.

Na ata, são 21 sócias cooperadas, no entanto, seis desistiram por dificuldades financeiras, por causa das retiradas que não chegam a um salário mínimo por mês. Há uma rotatividade muito grande, mulheres entrando e saindo da cooperativa. $\mathrm{O}$ grande desafio para a construção da sustentabilidade econômica da cooperativa é como se inserir de forma competitiva no mercado capitalista. Neste sentido, o foco do projeto da Central Solidária é permitir o acesso direto das cooperativas ao mercado, contudo, trata-se de um projeto incipiente e que precisa de tempo para conquistar fatias de mercado. "Precisamos ir atrás desse cliente certo", diz Lúcia, a presidente da cooperativa. Para isso falta-lhes o conhecimento de identificar oportunidades de vendas, de lidar e de negociar com os clientes. Atualmente os principais clientes estão nas feiras populares, onde as cooperadas vendem de $\mathrm{R} \$ 30$ a $\mathrm{R} \$ 50$ por dia, e a ONG Visão Mundial, que encomenda peças em grande escala, são pedidos de R\$300 a R \$ 1.000.

Contudo, a meu ver, para além da motivação estritamente econômica, há outras motivações e interesses relacionados às lutas sociais e ao projeto da economia solidária do modo como é re-significada por essas mulheres e homens. São essas motivações e interesses que explicam a permanência dessas mulheres na cooperativa, a despeito de não conseguirem extrair nem um salário mínimo mensal.

Lúcia Vieira mora no bairro Santa Filomena, distante 16 quadras da cooperativa situada no Conjunto
Palmeiras. É sócia da cooperativa desde o início, atualmente ocupa o cargo de presidente, é casada e mãe de dois filhos adolescentes que estudam. Desde a sua adolescência se envolveu com os movimentos da igreja católica, trabalhou no mercado formal, no ramo de confecção em Fortaleza durante 14 anos. Lúcia aprendeu o sentido profundo da reciprocidade e da economia solidária principalmente com os padres vinculados à Pastoral Operária, que lhes falavam sobre a utopia da nova sociedade. A semente plantada, que mesclou espiritualidade e luta social, deu bons frutos, como Lucia me explicitou nesse relato exemplar,

\begin{abstract}
Quando eles chegaram, tudo mudou. Antes não tinha nada, não tinha água, não tinha luz, não tinha saneamento, não tinha ônibus, tinha só um, uma vez por dia que vinha e voltava. Eles foram embora para Timor Leste em março de 2004. Eles passaram 17 anos aqui, chegaram em 1989, eu me casei em 1988. No Santa Filomena. Sem filhos. Era a maior dificuldade do mundo, a vida era muito precária, por isso todo mundo chama aqui de terra dos índios, porque, era tudo muito rústico, muito pobre. Faz pouco tempo que fizeram essa avenida. Foi um desenvolvimento pela ação dos padres. Foi a luta do povo que eles fermentavam, articulavam. Eles conseguiram fazer um trabalho: a conscientização política. A luta não era pelo Palmeiras, não era uma coisa por família tal, não era individualista; eles mostraram para a gente sempre o geral. O povo passa fome, as mulheres sofrem, os políticos, não fazem nada, como ainda não estão fazendo. Só que o povo agora não está mais besta. Mudou a conscientização, a forma de trabalhar, que agora é cooperativismo. Agora a gente está com a mente mais aberta para o mundo.
\end{abstract}

Lúcia permanece na cooperativa porque acredita de forma lúcida na transformação da sociedade e na construção de uma nova sociabilidade, e, como mãe, acredita que com sua ação vai deixar uma sociedade melhor para os seus filhos viverem.

Francisca Ferreira Gomes também está desde o início na cooperativa, trabalhou por alguns anos em uma empresa de confecção, com carteira assinada. É mãe de cinco filhos que estudam, sofreu durante longo tempo violência de gênero, o marido a abandonou, atualmente é sócia cooperada, cria e sustenta sozinha os seus filhos. Ela não tem o mesmo nível de compreensão de Lucia acerca do projeto da economia solidária. Sabe, porém, exatamente o valor da reciprocidade e da solidariedade na esfera da produção e fora dela, pois, assim como Lucia e as outras cooperadas, ela não separa o trabalho das demais esferas da vida, como a família, a fé religiosa e os demais laços sociais. 


\section{Caso 2: Cooperativa de Crédito Rural de Jaguaretama}

A Cooperativa de Crédito Rural de Jaguaretama, constituída em sua grande maioria por assentados da reforma agrária, está localizada no município de Jaguaretama situado na região do semi-árido cearense e na microrregião do Médio Jaguaribe, de clima tropical quente semi-árido, distante $245 \mathrm{~km}$ da capital do estado ${ }^{9}$. A paisagem, de janeiro a abril, no período chuvoso, é bonita, exibe 200 quilômetros de vegetação verde, composta por cajueiros, flores silvestres, carnaúba, belos açudes e cactos solitários. No período da estiagem, predomina uma vegetação seca e árida. A temperatura média oscila entre 26 e $28^{\circ} \mathrm{C}$, e o índice pluviométrico é de $782,8 \mathrm{~mm}$. O município possui uma população estimada em pouco mais de 18 mil habitantes, dos quais, 10 mil, aproximadamente, atuam na agricultura. A atividade base do município é a agricultura familiar - feijão, milho, mandioca, sorgo - e a pecuária - bovino e ovinocaprinocultura. A agropecuária contribui em $36,7 \%$ para o PIB local, enquanto que o setor de serviços em $50,8 \%$, e a indústria em $12,5 \%$. No ano de 2003, o PIB per capita era de R\$ 2.200. Há uma taxa de urbanização que oscila em torno de $40,47 \%$, enquanto o IDH é de 0,645, qüinquagésima oitava cidade mais pobre do Estado no Ceará (ANUÁRIO ESTATÍSTICO DO CEARÁ, 2006).

Os relatos dizem que a origem da Cooperativa de Crédito Rural de Jaguaretama remonta ao 1997, no contexto dos debates realizados nos assentamentos de reforma agrária situados no Vale do Jaguaribe ${ }^{10}$. Contudo, a temática do cooperativismo no universo dos assentamentos fora introduzida pelo Sindicato dos Trabalhadores Rurais (STR) no decurso da 'luta pela terra', que se iniciou no município de Jaguaretama, em meados dos anos 1960, a partir dos conflitos de interesses entre o proprietário das terras e os trabalhadores rurais que residiam com suas famílias e trabalhavam nessas terras. Segundo os relatos, foram aproximadamente de 17 a 20 anos de 'lutas' envolvendo os trabalhadores e as suas famílias, o STR, o poder público municipal e o sistema judiciário local. A primeira desapropriação ocorreu em 1987, dando origem à comunidade Serrote Branco situada a 32 $\mathrm{km}$ do centro de Jaguaretama ${ }^{11}$. Em 2007, existem em Jaguaretama 13 assentamentos de reforma agrária e, aproximadamente, 642 famílias assentadas ${ }^{12}$.

A Cooperativa de Crédito Rural de Jaguaretama ${ }^{13}$ está vinculada à Articulação no Semi-Árido Brasileiro (ASA), à ADS e esteve, durante três anos, ao Sistema Nacional de Cooperativas de Economia e Crédito Solidário (Ecosol), foi formalizada no dia 16 de março de 2002 e começou a funcionar em 2003 com 36 sócios-cooperados - lideranças comunitárias dos assentamentos de reforma agrária -, com capital social de $\mathrm{R} \$ 4.380$ e está funcionando no Sindicato dos Trabalhadores Rurais, no centro de Jaguaretama. A cooperativa fornece crédito e poupança aos pequenos agricultores rurais dos assentamentos da reforma agrária, que estão, em sua maioria, vinculados à Federação dos Trabalhadores na Agricultura do Estado do Ceará (Fetraece) ${ }^{14}$. Raimundo Eudivan da silva (atual presidente e sóciofundador da cooperativa) me relatou que,

A cooperativa já nasceu com as lideranças dos assentamentos, na época eu era assentado. Trabalhávamos nas comunidades para falar sobre as cooperativas, e quem tinha mais conhecimento eram as lideranças. O pessoal do Banco Palmas veio dar uma palestra para a gente. A cooperativa foi fundada com 36 sócios-fundadores, nós fazíamos promoções, rifas. Nós trabalhamos com 36, e nós íamos a cada comunidade discutir cooperativismo. Em 2002 foi formalizada, fizemos uma festa e arrecadamos dinheiro, depois disso ficamos parados no tempo. De 2002 até 2004 ficamos parados.

Nessa fase inicial foram assessorados pela ADS, que ministrou o curso de socioeeconomia solidária, com duração de 120 horas (com recursos do Fundo de Amparo ao Trabalhador-FAT), e disponibilizou um gestor de negócios e um contador para assessorar diretamente a cooperativa durante um período de 18 meses.

A cooperativa conta atualmente com 95 cooperados, na sua maioria homens 'chefes' de família e lideranças dos assentamos da reforma agrária, conta também com alguns técnicos em agropecuária que atuam em uma empresa privada de assistência técnica na área de agricultura, a Comatec. Atualmente a cooperativa conta com um capital social de $\mathrm{R} \$ 8.000$ e uma poupança de $\mathrm{R} \$ 3.000$. A cooperativa disponibiliza crédito (até $\mathrm{R} \$ 300$ ) cobrando $3 \%$ ao mês com juros simples-regressivo, enquanto que o sistema bancário cobra geralmente $4,5 \%$ com juros compostos (juros iguais da primeira parcela até a última). E oferece um sistema de poupança que rende $0,8 \%$ ao mês. A média do valor de cada empréstimo é de R\$300, a serem pagos em seis meses. A inadimplência situa-se em $50 \%$, em muitos casos por dificuldades financeiras da família. $\mathrm{Na}$ seca (oito meses) ficam devendo, na estação chuvosa (quatro meses) saldam as suas dívidas, disse-me o presidente. A garantia exigida do solicitante pela cooperativa é o aval da comunidade, ou seja, se ele é bom pagador do ponto de vista do grupo local. Os cooperados exercem como atividade central a agricultura, a pecuária e alguns praticam a apicultura, para subsistência da família. Quando há excedentes vendem para o comércio local: supermercados, mercadinhos, armazéns e feiras locais. Os pequenos agricultores enfrentam o problema do atravessador. Esse, muitas 
vezes, de outro município, vende a um preço inferior só para ganhar o mercado local, fator que tem por conseqüência desestimular o agricultor.

Atualmente estão desligados do sistema Ecosol que media as relações entre a cooperativa de crédito e o Banco Central (BC), o qual regula as atividades do Sistema Financeiro Nacional (SFN), dentre elas as atividades das cooperativas de crédito solidário. $\mathrm{O}$ BC estipula metas financeiras para as cooperativas de crédito, como ampliação progressiva do número de cooperados, do capital social, da poupança e a redução gradativa da inadimplência. Por não terem atingidos as metas foram desligados do sistema, e, em 2007, a sua sobrevivência como cooperativa de crédito está seriamente ameaçada. Segundo o modelo Ecosol a cooperativa teria que atuar combinando os princípios da rentabilidade segundo regulamentação do BC e os princípios da economia solidária. Como articular metas financeiras e solidariedade? Ou como por meio da solidariedade atingir metas financeiras? Eis o grande desafio posto à cooperativa do semi-árido cearense

No início, os cooperados, assessorados pela ADS e pelo Sistema Ecosol, realizaram empréstimos, incorporaram novos sócios que pagavam os débitos com a cooperativa. $\mathrm{O}$ dinheiro (capital social) circulava na cooperativa. $\mathrm{O}$ que faltou na visão do primeiro presidente, Josias Gomes de Freitas (2002-2005), e na do atual, Raimundo Eudivan da Silva (2006-), foi construir e garantir a sustentabilidade da cooperativa. Josias fala sobre as metas estabelecidas pelo BC e sobre as limitações da cooperativa em atingir as metas,

Foi difícil a gente atingir uma meta de crescimento que tornasse a cooperativa viável e sustentável. Para que seja uma cooperativa de alta sustentação, é preciso que ela tenha um crescimento exigido por nós (cooperados) e pelo BC. O BC estabelece metas com muita rigidez para as cooperativas de crédito. A Ecosol também estabelece metas olhando para os critérios do BC. O sistema trabalha dentro dos normativos do BC. Se a cooperativa não crescer o Sistema não vai querer mais a cooperativa no seu quadro. O bom desempenho seria o crescimento do número de cooperados e de capital de giro, de poupança, recursos, patrimônio. O BC diz então que cooperativa de crédito com cinco anos tem que ter 300 cooperados. A lei trata todas iguais independentemente da localização regional.

Em princípio, várias experiências demonstram que não há incompatibilidade entre solidariedade e rentabilidade, a exemplo do Grameen Bank, da Cooperativa de Crédito de Pajeú em Pernambuco, ligada ao Sistema Ecosol, e a experiência exemplar do Banco Palmas na cidade de Fortaleza ${ }^{15}$. Pelo contrário, a solidariedade construída nas relações sociais dos as- sociados pode ser uma dimensão significativa no combate à pobreza e na gestação de empreendimentos econômicos sustentáveis, inclusive, do ponto de vista da rentabilidade.

Contudo, muitas cooperativas de crédito rural formadas sob a perspectiva da economia solidária enfrentam um dilema: como gerar lucro e solidariedade ao mesmo tempo? Como se tornar rentável da perspectiva do Sistema Financeiro Nacional (SFN) e combater a pobreza no meio rural? Segundo Alves e Soares (2006, p. 39), essas instituições se tornam rentáveis quando atingem a marca de 10 mil clientes ativos: "No Brasil, as leis e normas que dizem respeito a esse segmento exigem o cumprimento dos mesmos fundamentos e princípios aplicáveis às demais instituições que compõem o SFN." Há controvérsias sobre a regulamentação das cooperativas de crédito. Da perspectiva do BC, a regulamentação e a atuação conforme as leis do mercado financeiro são importantes para a sustentabilidade, a autonomia e a viabilidade econômica da cooperativa. No entanto, técnicos do BC afirmam que a atuação articulada nessas dimensões exige um nível de consciência e de reflexividade coletiva difícil de germinar em um contexto socioeconômico que não propicia o exercício da cidadania, da justiça, da educação e o acesso à informação. Eu acrescentaria mais um elemento a esse rol: o acesso e a capacitação às tecnologias de informação, uma vez que a cooperativa de credito é monitorada on-line e em tempo real, pelo Sistema e pelo BC.

A esse respeito Alves e Soares (2006, p. 40) afirmam que:

\footnotetext{
Com efeito, por ser uma sociedade de pessoas, é a qualidade dessas pessoas que faz um projeto cooperativista avançar, criar raízes, desenvolver-se de forma continuada. Quando o corpo cooperado é formado por pessoas com baixo grau de escolaridade, que vivem em regiões pobres, a análise empírica tem demonstrado que o crescimento é lento, instável e necessita apoio externo para se manter. Ressalte-se que esse apoio externo representa subsídio e só deve ser utilizado na fase inicial do projeto de constituição da cooperativa, por ser incompatível com a auto-sustentabilidade, fator essencial para a sua continuidade e desenvolvimento pleno, autônomo e transparente e independente.
}

Concordo com a argumentação das autoras, contudo, elas, assim como o secretário da agricultura, não questionam as raízes históricas e estruturais da pobreza e do baixo nível de escolaridade, portanto, do baixo 'nível de consciência' ${ }^{16}$. Não é que essas pessoas pobres tenham um baixo nível de consciência coletiva em função da sua baixa escolaridade que é um fato constatado nesta etnografia. Trata-se, po- 
rém, de se indagar, em primeiro lugar, que sociedade é essa que permite ou que engendra essas pessoas pobres e com baixa escolaridade! Meu saudoso professor Octávio Ianni dizia em sala de aula que as nossas elites historicamente estabeleceram um laço débil com o seu povo e com os interesses da nação.

Em segundo lugar, é necessário identificar as raízes históricas de nossa pobreza e de nossa baixa escolaridade, e em terceiro lugar, é preciso sensibilidade analítica para ver que essas pessoas pobres incorporam o crédito solidário e a cooperativa de crédito a partir de suas próprias categorias simbólicas, engendradas historicamente nas relações clientelistas. Isto é, essas pessoas pobres (re)significam o crédito solidário a partir do clientelismo político ${ }^{17}$.

Assim, como os cooperados não opõem solidariedade e clientelismo, a solidariedade pode ser uma ferramenta poderosa para a rentabilidade, mas para tanto, é preciso que as pessoas transcendam a lógica clientelista. Portanto, o que limita a rentabilidade dos empreendimentos não é somente a baixa escolaridade nem a ausência de consciência coletiva, mas, sim, relações sociais ancoradas no clientelismo político, raízes históricas da pobreza e da baixa escolaridade no universo dos assentados.

Os nossos cooperados não opõem solidariedade e clientelismo, contudo articulam essas duas dimensões no plano simbólico. E, à medida que (re)significam o crédito solidário, a partir das relações clientelistas, reproduzse a assimetria estrutural, ela mesma construída historicamente por meio das relações de dominação política (FAORO, 2000; TAVARES, 2000; CHAUÍ, 2000). A respeito das relações entre estrutura e evento Shalins (1999, p. 182) diz:

\begin{abstract}
Ele [Cook] é um Deus. Este conhecimento, porém e uma espécie de reconhecimento. O evento é inserido em uma categoria preexistente e a história está presente na ação corrente. O surgimento de Cook, vindo de além do horizonte, fora realmente um evento sem precedentes, jamais visto antes. Mas, por assim abarcar aquilo que e realmente singular naquilo que e conceitualmente familiar, introduz o presente no passado.
\end{abstract}

Tanto quanto Sahlins (1999) - como no caso etnográfico -, que relata a experiência contemporânea dos nossos pequenos agricultores assentados que vivem no semi-árido cearense, podemos considerar o crédito solidário como o evento que incorporaram no plano simbólico a partir de suas próprias categorias, introduzindo, desta forma, o passado no presente. Podemos nos perguntar, afinal de contas as coisas mudaram? Sim, mudaram, mas não o suficiente para romper com as relações de dominação e de dependência do poder local e do poder central.

Após o embate pela democratização do acesso à terra, que se iniciou nos anos 80, a Secretaria da Agricultura tem realizado atividades de cooptação dos movimentos sociais na região, desenvolvendo políticas para institucionalizá-los. Para tanto, a atual gestão contratou um agente, oriundo dos movimentos sociais, particularmente nos assentamentos para mediar a relação entre o poder público e os assenta$\operatorname{dos}^{18}$. O papel do agente é legalizar a situação das associações, coordenar o fórum dos assentamentos e desenvolver projetos para as associações com a finalidade de trazer recursos do governo federal para o pequeno agricultor. Os assentados têm direito por lei ao Programa Nacional de Fortalecimento da Agricultura Familiar (Pronaf) e ao Bolsa-Escola, e o município recebe recursos da Federação Comunitária de Pernambuco (Fecope). Além disso, estão tendo a oportunidade de se candidatarem ao projeto da Companhia Nacional de Abastecimento (Conab), mas todos os benefícios que recebem os assentados têm a mediação do poder público local - da prefeitura por meio da secretaria da agricultura. Se por um lado, parece, à primeira vista, um apoio do poder público local, por outro, reforça a dependência dos assentados nessa direção, ou seja, o movimento está sempre monitorado. As ações desenvolvidas pela prefeitura por meio da Secretaria da agricultura permitem que a retórica sobre a desigualdade social e o combate a ela sejam acionados e capitalizados politicamente no plano ideológico (falsa consciência), fato que reproduz as relações estruturais baseadas no clientelismo político ${ }^{19}$. Poderíamos olhar as relações entre o movimento social dos assentados e o poder público local como uma relação de troca que, se não instaura, reproduz a assimetria ${ }^{20}$. Neste caso, dar, inicialmente, parece instituir uma relação dupla entre o doador e aquele que recebe, porém o dom institui uma assimetria, aquele que recebe se torna devedor. Segundo Godelier (2001, p. 231),

Dar parece instaurar assim uma diferença e uma desigualdade de status entre doador e donatário, 
desigualdade que em certas circunstancias pode se transformar em hierarquia: se esta já existisse entre eles antes do dom, ele viria expressá-la e legitimá-la ao mesmo tempo. Portanto, dois movimentos opostos estariam contidos em um único mesmo ato. O dom aproxima os protagonistas porque é partilha e os afasta socialmente porque transforma um deles em devedor do outro.

De fato, há um conjunto de fatores que limitam o desenvolvimento da cooperativa, como o isolamento geográfico de Jaguaretama, a falta de conhecimento técnico e de escolaridade formal. Os cooperados, contudo, ao invés de se mobilizarem e de se organizarem coletivamente para a poupança na cooperativa, esperam receber apoio financeiro de entidades externas. Os relatos etnográficos revelam que a maioria dos cooperados, que são também os assentados, incorpora o crédito ‘solidário' a partir de uma visão imediatista e pragmática. Uma visão de mundo baseada nas relações estruturais de clientelismo que, de certa forma, impede que os pequenos agricultores incorporem em suas vidas cotidianas o sentido do crédito solidário, da auto-gestão e da solidariedade como um instrumento de crítica, de negação e superação da sociedade capitalista e, portanto, de emancipação social (HABERMAS, 1987).

Josias Gomes expressou o seu sentimento de tristeza, que também é o meu, como pesquisadora e cidadã que se solidariza com todas aquelas pessoas honestas e trabalhadoras que conheci tão de perto,

É uma tristeza para nós - uma entidade tão importante da socioeconomia solidária (uma cooperativa de crédito) que poderia ser estar fazendo um papel do banco -, pois, ao invés de estarmos dando os nossos lucros aos grandes banqueiros, podíamos estar dando para nós mesmos na cooperativa, mas o povo não acreditou. Nós falamos muito nisso, em diversas oportunidades, diversas e diversas conversas e palestras. A gente falava para o povo, mas a gente não foi acreditado. Não abriram a mente para isso, não abriram a inteligência para dizer assim 'vamos sair do capitalismo e vamos para o socialismo direto'. Não aconteceu, para nós é uma tristeza.

\section{Considerações finais}

Em 2008, será que poderemos atribuir à solidariedade o potencial de evitar a desagregação do tecido social? Ela poderá se constituir como uma fonte fecunda que leve à emancipação social? Terá a solidariedade o potencial de combater a pobreza, a desigualdade de renda e a exclusão social? Se assim for, a solidariedade poderia vir a servir de inspiração para a formulação de políticas públicas de caráter social?
A solidariedade poderia vir a servir de base à formação de um novo modelo econômico, a economia solidária, fundada em novas formas de sociabilidades, em novos valores e em uma nova ética?

Não há respostas simples. Permito-me realizar uma singela reflexão a partir da etnografia que realizei dos empreendimentos econômicos solidários (ausentes deste artigo por razões de limites de páginas) e da ADS no Estado do Ceará buscando pelos significados que essas experiências ou casos etnográficos nos revelaram por meio dos relatos de homens e mulheres - bravos, trabalhadores e corajosos -, que vivem e trabalham nas regiões mais 'pobres' de Fortaleza e na região semi-árida.

Em alguns empreendimentos, a lógica de coordenação da ação são os interesses sistêmicos da reprodução ampliada do capital, a exemplo da cooperativa de pescadores da Praia do Forte, constituída por donos de barco, a partir da iniciativa de um grande empreendimento capitalista o complexo turístico Porto Sauípe. O grande desafio posto à comunidade é o de como colocar a identidade e a tradição cultural a serviço da geração de renda e da emancipação social. Porém, em outras experiências, identifiquei laços profundos de solidariedade e uma intensa compreensão do sentido da economia solidária e de seu papel no desenvolvimento local, na geração de renda, na melhoria das condições de vida das pessoas mais pobres e na gestação de novas formas de sociabilidade fundadas em valores solidários e em uma nova ética. Identifiquei também casos etnográficos em que o dom se reveste de forma assimétrica e reproduz a desigualdade social, assim como casos em que um novo sentido de vida e uma nova identidade social foram construídos a partir dessas experiências.

A despeito de suas singularidades, a maioria dos empreendimentos enfrenta o mesmo conjunto de discriminações negativas, persistentes na esfera do mercado e na esfera do ordenamento jurídico ${ }^{21}$, quanto a:

a) mercado, na identificação de nichos de mercado onde o empreendimento seria competitivo;

b) escala de produção;

c) produção com maior valor agregado;

d) marco legal adequado;

e) acesso ao crédito,

f) acesso às informações;

g) ausência de assistência técnica e acompanhamento e

h) políticas públicas ${ }^{22}$.

As entidades de apoio e de fomento à economia solidária desempenham papel de destaque na formação em cooperativismo, auto-gestão, em economia solidária e no acompanhamento dos empreendimentos. Neste sentido, no plano de formação das consciências para cidadania, auto-gestão, cooperativismo e adoção de novos valores elas vêm tendo uma conduta exemplar. Contudo, nenhuma entidade tem força sufi- 
ciente para intervir nas regras de mercado, no marco legal e na cultura política, três dimensões estruturais, onde residem as maiores limitações à expansão e à viabilidade econômica dos empreendimentos.

O atual secretário nacional da economia solidária, Paul Singer, observa que no plano institucional uma das maneiras de superar as fragilidades, em especial no Nordeste, é a articulação entre agências de fomento como a ADS, Cáritas, Anteag e as incubadoras, conjuntamente com as cooperativas e associações. Encerro estas considerações retomando o paradoxo do dom, segundo Godelier (2001). A mesma economia que cria os excluídos em massa confia à sociedade a tarefa de (re)incluí-los, não na economia, mas no tecido social, acrescento eu, por meio das políticas públicas de caráter social institucionalizadas pelo Estado, dentre elas, as que intervêm no campo da economia solidária e dos empreendimentos, por meio da atuação de entidades como a ADS.

\section{Referências}

ALVES, S.; SOARES, M. Microfinanças. Democratização do crédito no Brasil. Atuação do Banco Central. Brasília: BCB, 2006.

ANUÁRIO ESTATÍSTICO DO CEARÁ 2006 [do] Governo do Estado do Ceará. Indicadores demográficos. Disponível em: < http://www.ipece.ce.gov.br/publicacoes/anuario/>. Acesso em: jun 2007.

AQUINO, M. Socioeconomia solidária: Uma nova sociedade possível. In: SEMINÁRIOS MAPP, 1. Políticas Públicas de microcrédito, economia solidária e a geração de trabalho e renda. Anais... Fortaleza, 2007.

BOURDIEU, P. Razões práticas sobre a teoria da acção. Oeiras: Celta, 1997.

BRAGA, E. Socioeconomia solidária e a questão democrática desvendando caminhos e utopias. Revista de Ciências Sociais, Fortaleza, v. 35, n.1, p.57-67, 2004.

CHAUÍ, M. Brasil: mito fundador e sociedade autoritária. São Paulo: Fundação Perseu Abramo, 2000.

ECOSOL. O que é o sistema Ecosol? Disponível em; <www.ecosol.com.br>. Acesso em: 08 nov.2007.

FAORO, R. Os donos do poder. Formação do patronato político brasileiro. São Paulo: Globo/Publifolha, 2000. (Grandes Nomes do Pensamento Brasileiro, v. 1).

FRANÇAFILHO, G. C.; SILVAJÚNIOR, J. T. Uma dinâmica associativa emblemática no Nordeste Brasileiro. In:
FRANÇA FILHO, G. C. et al. Ação pública e economia solidária: uma perspectiva internacional. Porto Alegre: Editora da UFRGS, 2006. p. 97-116.

GAIGER, L. (Org.). Sentidos e experiências da economia solidária no Brasil. Porto Alegre: Editora da UFRGS, 2004.

GODBOUT, J. Homo donator versus homo oeconomicus. In: MARTINS, P. (Org.). A dádiva entre os modernos. Discussão sobre os fundamentos e as regras do social. Rio de Janeiro: Vozes, 2002. p. 63-98.

GODELIER, M. O enigma do dom. Rio de Janeiro: Civilização Brasileira, 2001.

HABERMAS, J. Teoría de la acción comunicativa. Critica de la razón funcionalista, v. 12. Madrid: Taurus, 1987.

LANNA, M. A divida divina. Troca e patronagem no nordeste brasileiro. Campinas: Editora da Unicamp, 1995.

LAVILLE, J.-L.; FRANÇA FILHO, G. Introdução. In: FRANÇA FILHO, G. C. et al. Ação pública e economia solidária: uma perspectiva internacional. Porto Alegre: Editora da UFRGS, 2006. p.11-17.

LECHAT, N. Economia social, economia solidária, terceiro setor: do que se trata? Civitas, Porto Alegre, v. 2, n.1, p. 123-140, jun. 2002.

MAUSS, M. Ensaio sobre a dádiva. Formas e razão de trocas nas sociedades arcaicas. In: _. Sociologia e antropologia. São Paulo: EDUSP, v. II, p.37-68, 1974.

PASTORAL OPERÁRIA. Experiência de trabalho alternativo. São Paulo: Colegiado Nacional da Pastoral Operária, 2005.

PAULINO, A. A socioeconomia solidária na experiência do Banco Palmas. In: CONGRESSO BRASILEIRO DE SOCIOLOGIA, 13, 2007. Recife. Anais...UFPE, Recife, 2007

PINHEIRO, M. Cooperativas de crédito: história da evolução normativa no Brasil. Brasília: BCB, 2006.

POLANYI, K. A grande transformação. As origens de nossa época. Rio de Janeiro: Elsevier, 2000.

SAHLINS, M. Ilhas de história. Rio de Janeiro: Jorge Zahar Editor, 1999.

SENAES. Atlas da economia solidária no Brasil. Brasília: MTE/Senaes, 2006.

TAVARES, M. Subdesenvolvimento, dominação e luta de classes. In: . (Org.). Celso Furtado e o Brasil. São Paulo: Fundação Perseu Abramo, 2000. p. 129-154. 


\section{Notas}

1 Sobre a aplicação da noção de campo na economia solidária, consultar Lechat (2002).

2 A etnografia dos empreendimentos é o resultado de uma pesquisa de campo articuladaa umareflexãoteórica realizadaao longo de três anos, de 2004 a 2007, no programa de pesquisa desenvolvimentocientíficoregional(DCR)doConselhoNacional de Pesquisa e Desenvolvimento (CNPq): Convênio Funcap que financiou a pesquisa desenvolvida no Programa de PósGraduaçãoem Sociologia, da Universidade Federal do Ceará.

3 Neste artigo, optei por citar o nome dos entrevistados com as suas respectivas autorizações via e-mail e pessoalmente no contexto das respectivas entrevistas. Optei ainda, por manter as falas em sua originalidade, por expressarem visões de mundo particulares atadas às determinadas tradições culturais, como diria Lévi-Strauss, próximas à experiência sensível dos sujeitos entrevistados, neste sentido, muitas vezes, as falas não apresentam aparentemente uma linha de argumentação e de racionalidade que consideramos da perspectiva positivista 'linear'( com começo, meio e fim).

4 Sobre a noção de empreendimentos econômicos solidários, inspiro-meem Gaiger(2004).

5 Iniciei a aproximação etnográfica juntoà Coopsol no segundo semestre de 2006 por indicação da coordenação estadual da ADS. Ocorreram quatro encontros onde realizei entrevistas qualitativas, conversas informais, entrevista com grupo focal, registros visuais e participei como observadora de uma reunião (que foi filmada) na sede da cooperativa no bairro João Paulo e do lançamento do livro de Manoel Evangelista, um dos personagens centrais dessa história que se autoidentifica como poeta popular. Hoje em dia (novembro/2007) mantenho contato com as cooperadas por telefone.

6 Braga afirma (2004, p. 60) que no mesmo período estava se gestandoaAssociação de Moradores do Conjunto Palmeiras (Asmoconp) que seria um dos protagonistas centrais da constituição do Banco Palmas, em 1988. "Fortaleza, como também outras cidades brasileiras, foi cenário de numerosas mobilizações da população no final da década de 70 e, nos anos 80, gestou diferentes formatos organizativos. É nesse contexto que surgem vários movimentos de bairros, dentre os quais merece destaque a Associação de Moradores do Conjunto Palmeiras (Asmoconp) por aglutinar diferentes forças sociais, sedimentando aprendizados e saberes, que consolidaram, ao longo de três décadas, deferentes tempos políticos. Os moradores desencadearam várias lutas: por moradia digna, por infra-estrutura, por escola, por transporte, por saúde, enfim, por uma vida digna." Aolado daAssociação Santos Dias, surgiria a Asmoconp e o Banco Palmas.

7 "O Conjunto Palmeiras está situado no bairro Jangurussu, próximo ao trecho da Rodovia BR 116 que contorna parte do bairro Messejana, na cidade de Fortaleza/CE. Sua população é estimada em 30.000 habitantes (IBGE, 2001). Há 33 anos (1973), iniciava-se o assentamento das primeiras famílias, oriundas de diferentes áreas de risco da cidade e também de regiões centrais onde a especulação imobiliária já impulsionava a expulsão de famílias assentadas em espaços que passaram a interessar no processo de 'modernização' da capital do Ceará. Assim, o povoamento do Conjunto Palmeiras deu-se a partir de uma ação executada pela Prefeitura Municipal de Fortaleza, em plena vigência do autoritarismo desenvolvimentista que caracterizou o governo dos militares" (PAULINO, 2007,p.3).

8 Cadagrupoé autônomo para comprar matéria-prima, produzir, comercializar, solicitar recursos e distribuir os recursos financeiros.

9 Estive em Jaguaretama nos dias 4 de dezembro de 2006, 13 de abril, 17 e 18 de maio de 2007, realizando entrevistas qualitativas com o primeiro diretor da cooperativa, com o atual diretor, com os sócio-cooperados e com o secretário de agricultura. Além das entrevistas qualitativas realizei uma entrevista com grupo focal composto por seis sócios e o diretor, que foi filmada. Participei, no dia 21 de junho de 2007, das comemorações dos 19 anos da conquista da terra na comunidade do assentamento Serrote Branco. Nessa ocasião, realizei entrevistas com os assentados sobre o processo de luta pela terra e o evento foi filmado. Estive na prefeitura e na secretaria da agricultura colhendo dados quantitativos do município com o chefe de gabinete e a secretária do prefeito, Ariosvaldo Saldanha do PSDB. Além dessas, realizei em Fortaleza, no dia 25 de abril de 2007, uma entrevista com o coordenador de articulação comunitária responsável pelos assuntos dos assentamentos do município. Em Jaguaretama, existem cadastradas 77 associações comunitárias e uma cooperativa: a Cooperativa de Crédito Rural.

10 Segundo Pinheiro (2006, p. 8), as cooperativas de crédito surgiram naAlemanha em 1848. No Brasil, em 1902, no Rio Grande do Sul, no município de Nova Petrópolis, a Caixa Rural de Nova Petrópolis. As sociedades cooperativas foram instituídas pela lei 5.764 de 16 de dezembro de 1971.

11 Serrote Brancoé o nome de uma colina cheia de árvores que fica 'branca' no verão em virtude da queda das folhas.

12 Dados obtidos através de entrevista realizada nos dias 17 e 18 de maio de 2007 como Secretário daAgricultura (gravada e transcrita) e com o agente contratado em 2004 pela prefeitura responsável pelos assuntos das associações comunitárias dos assentamentos, o coordenador de articulação comunitária. A quantidade exata de famílias assentadas não é possível estabelecer, Eudivan, por exemplo, afirmou que existem atualmente algo em torno de 700 famílias assentadas o que significa um número aproximado de 3.000 pessoas assentadas no município. 
13 A Cooperativa de Crédito Rural de Jaguaretamaé classificada pelo Banco Central do Brasil (BC) como uma cooperativa singular ou de primeiro grau, destinada a prestar serviços financeiros diretamente aos associados. Segundo Pinheiros (2006), as cooperativas de crédito são instituições financeiras que compõem o Sistema Financeiro Nacional (SFN), sujeitas às normas estabelecidas pelo $\mathrm{BC}$.

14 ACooperativa deCrédito Rural de Jaguaretamaestá vinculada ao Sistema Ecosol composto por uma central situada em São Paulo, uma base regional e 26 singulares. "O Ecosol é um sistema de apoio a cooperativas de crédito solidário, como forma de promover o fortalecimento da economia solidáriae do desenvolvimento sustentável" (ECOSOL, 2007).

15 Sobre o caso do Banco Palmas, consultar França Filho e Silva Júnior(2006).

16 Ao lado da pobreza, da baixa escolaridade, a violência é outro elemento que faz parte do cotidiano dos assentados. Segundo notícia veiculada pelo Jornal O Povo do dia 6 de junho de 2007, Jaguaretama com 18.302 habitantes éo sétimo município mais violento em taxas de homicídios do Estado do Ceará, enquanto que Fortaleza com 2.374.944 habitantes é o nono. Eudivan me disse que há muitos conflitos nos assentamentos, contudo, nos municípios do Ceará há muitos crimes de pistolagem e conflitos entre famílias que disputam o poder político local.

17 "A história é ordenada culturalmente de diferentes modos nas diferentes sociedades, de acordo com os esquemas de significação. [...] Aestrutura é alterada historicamente, assim como a história (o acontecimento, o evento) é ordenado de acordo com o esquema de significação, de acordo com a estrutura"(SAHLINS, 1999, p. 7).

18 Entrevistei o agente responsável pelos assuntos dos assentamentos nos dias 25 de abril em Fortaleza e no dia 17 de maio de 2007 em Jaguaretama.

19 Shalins(1999,p.181) sobre as relações entre estruturae história dizque "No final, quanto mais as coisas permaneciam iguais, mais elas mudavam, uma vez que tal reprodução de categorias não é igual."

20 Trata-se do dom entre desiguais de que falam Lanna(1995)e Godbout(2002).

21 Conforme Laville e França Filho (2006, p. 299). Segundo os autores, uma das discriminações negativas é o atual marco legal que favorece as grandes estruturas cooperativas, como a do agrobusiness, cujo funcionamentoé o mesmo de outras empresas privadas e as falsas cooperativas que precarizam o trabalho. Por outro lado, "Os critérios, permitindo às autoridades públicas reconhecer as contribuições para a coletividade, fornecidas por atividades impõem, em primeiro lugar, finalidades de natureza sociais e ambientais, não são garantidos na França, e muito menos no Brasil, onde tal debate nem ao menos é colocado." Para os autores, os empreendimentos só vão sair de seu isolamento "com a introdução de políticas públicas opondo-se às discriminações negativas às quais elas são confrontadas", nesse processo há necessidade de pressão de forças organizadas da sociedade civil.

22 Segundo $o$ Atlas da Economia Solidária (SENAES, 2006), $61 \%$ dos EES afirmam ter dificuldades na comercialização dos produtos e serviços; $49 \%$ não têm acesso ao crédito e $27 \%$ não tiveram acompanhamento, apoio ou assistência técnica.

\section{Alicia Ferreira Gonçalves}

Doutora em Ciências Sociais/Unicamp

Professora visitante do Mestrado Profissional em Avaliação de Políticas Públicas (MAPP/UFC) e professora colaboradora do Mestrado em Desenvolvimento e Meio Ambiente (Prodema/UFC)

\section{MAPP}

Rua Marechal Deodoro s/n

Campus Benfica

Quadra da Faced (UFC) - Prédio do Nuper

mapp@ufc.br

www.mapp.ufc.br

\section{Prodema}

Centro de Ciências, Bloco 902

Campus do Pici

Fortaleza - Ceará

CEP: 60455-970 